УДК 657.9 JEL M41

\section{Жукова Ольга}

Владимировна

аспирант, ФГОБУ ВО «Финансовый университет при Правительстве

Российской Федерации», г. Москва, Российская Федерация

ORCID: 0000-0002-4660-6118

e-mail: olga_zhukova_92@mail.ru

\section{Zhukova Olga}

Postgraduate Student, Financial University under the Government of the Russian Federation, Moscow, Russia ORCID: 0000-0002-4660-6118 e-mail: olga_zhukova_92@mail.ru

\section{ОЦЕНОЧНЫЕ РЕЗЕРВЫ И ОЦЕНОЧНЫЕ ОБЯЗАТЕЛЬСТВА: ПРОБЛЕМА ТРАКТОВКИ В СИСТЕМЕ РОССИЙСКОГО НОРМАТИВНО- ПРАВОВОГО РЕГУЛИРОВАНИЯ БУХГАЛТЕРСКОГО УЧETA}

\begin{abstract}
Аннотация. Проведен анализ российской нормативно-правовой базы бухгалтерского учета оченочных резервов и оченочных обязательств коммерческих организачий на предмет существующего терминологического пространства, проблем соотнесения экономической сущности указанных учетных категорий и действующего законодательства, ценности корректного применения терминологии в бухгалтерской (финансовой) отчетности для широкого круга заинтересованных пользователей. Особое внимание уделено отличительным чертам оченочных резервов и оченочных обязательств в призме их экономической сущности. По результатам исследования сформулированы предложения в отночении трактовки понятий «оченочный резерв» и «оценочное обязательство» при реализации программь по реформированию российской системы нормативно-правового регулирования бухгалтерского учета и составления бухгалтерской (финансовой) отчетности.
\end{abstract}

Ключевые слова: оценочный резерв, оченочное обязательство, профессиональное суждение, бухгалтерская (финансовая) отчетность, ФСБУ, МСФО, бухгалтерский баланс, коммерческая организация.

Цитирование: Жукова О.В. Оценочные резервы и оценочные обязательства: проблема трактовки в системе российского нормативно-правового регулирования бухгалтерского учета//Вестник университета. 2020. № 5. С. 129-134.

\section{ESTIMATED RESERVES AND ESTIMATED LIABILITIES: THE PROBLEM OF INTERPRETATION IN THE SYSTEM OF RUSSIAN LEGAL REGULATION OF ACCOUNTING}

\begin{abstract}
The Russian legal framework for accounting of estimated reserves and estimated liabilities of commercial organizations for the existing terminology space, the problems of correlation of the economic essence of these accounting categories and current legislation, the value of correct application of terminology in accounting (financial) statements for a wide range of stakeholders has been analysed. Special attention has been paid to the distinctive features of estimated reserves and estimated liabilities in the prism of their economic essence. Based on the results of the study, proposals regarding the interpretation of the concepts of "estimated reserve" and "estimated liability" in the implementation of the program to reform the Russian system of legal regulation of accounting and preparation of accounting (financial) statements have been formulated.
\end{abstract}

Keywords: estimated reserve, estimated liability, professional judgment, accounting (financial) statements, FAS, IFRS, accounting balance, commercial entity.

For citation: Zhukova O.V. (2020) Estimated reserves and estimated liabilities: the problem of interpretation in the system of Russian legal regulation of accounting. Vestnik universiteta. I. 5, pp. 129-134. DOI: 10.26425/18164277-2020-5-129-134

В процессе реформирования учетной системы достижение единого терминологического пространства является одной из ключевых задач, которая в настоящий момент рассматривается как приоритетная.

Вопросам бухгалтерского учета и представления в бухгалтерской (финансовой) отчетности коммерческих организаций таких учетных категорий, как резервы и оценочные обязательства посвящены работы многих российских ученых, в частности Т. Ю. Дружиловской, Т. И. Калачевой, Н. А. Ухтеевой, Е. Ю. Дирковой,

(C) Жукова О.В., 2020. Статья доступна по лицензии Creative Commons «Attribution» («Атрибуция») 4.0. всемирная (http://creativecommons.org/licenses/by/4.0/).

The Author(s), 2020. This is an open access article under the CC BY 4.0 license (http://creativecommons.org/licenses/by/4.0/).

(c) (i) 
И. В. Бардиной, О. А. Замотаевой, О. А. Курбангалеевой, А. М. Петрова, Л. Ю. Мельниковой, О. В. Рожновой, В. П. Сидневой, М. Ю. Хомякова. Однако на законодательном уровне вопрос понятийного аппарата в отношении резервов и оценочных обязательств сегодня остается открытым.

Центральным моментом, который в своих работах рассматривает Т. Ю. Дружиловская, является экономическая сущность понятий «резерв» и «оценочное обязательство». В своей работе «Оценочные обязательства и резервы: трактовка и проблемы учета в системах российских и международных стандартов» ученый отмечает, что сущность резервов определяется их функциональной ролью в хозяйственной жизни организации: часть активов хозяйствующего субъекта, которая в текущем отчетном периоде отражается как запас ресурсов и которыми можно будет воспользоваться в будущем [5]. Что касается понятия «оценочное обязательство», то Т. Ю. Дружиловская обращает внимание на то, что, в первую очередь, это именно обязательство, а не часть активов, во вторую очередь - погашение такого обязательства приводит к оттоку активов хозяйствующего субъекта [5]. Иными словами, автор отмечет, что отождествление понятий «резерв» и «оценочное обязательство» является невозможным исходя из их экономической сущности, поскольку иначе получается, что понятия «активы» и «обязательства» тождественны, что методологически и экономически неверно.

В работе «Сравнительный анализ состава и содержания отдельных видов резервов в отечественной и зарубежной практике» А. М. Петров и Л. А. Мельникова отмечают, что в российской системе учета организации создают уставные и оценочные резервы и оценочные обязательства. Авторы уточняют, что к уставным резервам относятся предусмотренные законодательством Российской Федерации и соответствующие учредительным документам резервы, в то время как назначение оценочных резервов - уточнение и реальная оценка стоимости балансовых активов хозяйствующих субъектов [6]. В работе также подчеркивается, что согласно Торговому кодексу Германии резервы - это пассивные статьи бухгалтерского баланса, как и оценочные обязательства, в связи с чем выделяются условия отнесения фактов хозяйственной жизни организации к резервам или оценочным обязательствам (экономическая нагрузка, количественная определенность и несомненная обязанность оказать услугу третьей стороне) [6].

Анализ действующего федерального стандарта по бухгалтерскому учету оценочных обязательств и применяемого в международной практике стандарта финансовой отчетности в указанной области учета показал, что в данных положениях законодатель не отождествляет понятия «резерв» и «оценочное обязательство» [4]. Однако используемая коммерческими организациями на практике Инструкция по применению Плана счетов вступает в противоречия со сделанным Т. Ю. Дружиловской выводом о нетождественности указанных понятий, что она также отметила в ранее упомянутой работе [5]. Инструкция по применению Плана счетов содержит прямое указание на существование таких видов резервов, как:

- счет 14 «Резервы под снижение стоимости материальных ценностей»;

- счет 59 «Резервы под обесценение финансовых вложений»;

- счет 63 «Резервы по сомнительным долгам»;

- счет 82 «Резервный капитал»;

- счет 96 «Резервы предстоящих расходов» [3].

С точки зрения экономической сущности и отражения в бухгалтерской (финансовой) отчетности хозяйствующих субъектов приведенная А. М. Петровым и Л. А. Мельниковой классификация резервов на уставные и оценочные является очевидной. Однако выделение авторами оценочных обязательств на основании рассматриваемого правового акта можно оспорить, если не обращаться к экономической сущности описываемых в тексте инструкции понятий.

Если обратиться к экономической сущности предлагаемых рассматриваемой инструкцией резервов, то представление в бухгалтерской (финансовой) отчетности и экономическая сущность экономических категорий, учитываемых на счете 96 и на счетах 14, 59 и 63, существенным образом отличаются (при рассмотрении данного вопроса счет 82 не анализируется, так как отражение и экономическая сущность учитываемого на данном счете резерва не оспаривается, как и резервов, создаваемых из нераспределенной прибыли) [3].

В частности, экономические категории, относимые в системе счетов бухгалтерского учета на счет 96 , отражаются в бухгалтерском балансе преимущественно в строке «Оценочные обязательства» в IV и (или) $\mathrm{V}$ разделе формы в зависимости от сроков реализации (долгосрочные или краткосрочные обязательства) или в иных строках указанных разделов бухгалтерского баланса, что требует ведения раздельного учета 
указанных объектов учета в зависимости от сроков погашения [2]. В свою очередь резервы, учитываемые на счетах 14, 59 и 63, уменьшают балансовую стоимость соответствующих видов активов и в пассивной части бухгалтерского баланса не отражаются. Иными словами, счета 14, 59 и 63 являются контрактивными счетами, поскольку они уточняют балансовую стоимость активов (по аналогии со счетами учета амортизации основных средств и нематериальных активов), в то время как экономические категории, учитываемые на счете 96, не являются уточняющими категориями. Данный вывод также подтверждается областью применения МСФО (IAS) 37: настоящим стандартом не рассматриваются корректировки балансовой стоимости активов, к которым относятся амортизация, обесценение активов и сомнительная задолженность [1].

Резервам и оценочным обязательствам свойственно применение оценочного суждения составителей бухгалтерской (финансовой) отчетности при определении оценки и сроков реализации, в связи с чем целесообразным можно считать уточнение понятия «резерв» - «оценочный резерв», как это было отмечено в своей работе А. М. Петровым и Л. А. Мельниковой [6]. Еще одним объединяющих фактором понятий «оценочный резерв» и «оценочное обязательство» является применение профессионального суждения в отношении их оценки, что предопределяет их сложность с точки зрения учета и презентации в отчетности, что подтверждается М. Ю. Хомяковым [9]. Также обе категории не относятся к активам организаций.

Однако ключевым отличием понятий «оценочный резерв» и «оценочное обязательство» остается экономическая сущность, находящая отражение в их назначении: с одной стороны, уточнение балансовой стоимости активов, при которой не происходит их отток, а достигается более достоверная балансовая оценка имущества хозяйствующего субъекта, с другой - возникновение обязанности хозяйствующего субъекта, реализация которой приведет к оттоку активов. Иными словами, использование категории «резерв» в отношении фактов хозяйственной жизни, учитываемых на счете 96, является экономически некорректным.

На основе данного рассуждения предлагается внесение уточнений в Инструкцию по применению Плана счетов коммерческих организаций, которые минимизируют методологические ошибки в применении федеральных стандартов бухгалтерского учета и международных стандартов финансовой отчетности ее составителями и поспособствуют повышению практической ценности и доверию широкого круга заинтересованных пользователей к отчетности хозяйствующих субъектов, о важности которых в своей работе отмечают О. В. Рожнова и В. П. Сиднева [7; 8].

С целью соотнесения теоретических аспектов учетной науки с практикой были рассмотрены бухгалтерские (финансовые) отчетности трех крупнейших российских компании (по выручке согласно рейтингу РБК 500): ПАО «Газпром», ПАО «Нефтяная компания «Лукойл», ПАО «НК Роснефть» [13].

Согласно данным официального сайта ПАО «Газпром», на момент написания статьи широкому кругу лиц была доступна бухгалтерская (финансовая) отчетность указанного хозяйствующего субъекта за 2018 г. и за 9 месяцев 2019 г. Поскольку для анализа проблематики, затронутой в данной работе, необходимы пояснения к отчетности компании, была использованы данные за 2018 г.

По данным бухгалтерской (финансовой) отчетности ПАО «Газпром» за 2018 г. в разделах бухгалтерского баланса «Долгосрочные обязательства» и «Краткосрочные обязательства» на 31 декабря 2018 г. отражены оценочные обязательства на сумму 10071423 тыс. руб. и 45098652 тыс. руб. В представленных формах бухгалтерской (финансовой) отчетности информация о резервах (кроме резервного капитала) не выделяется. В пояснениях к указанным формам отчетности отражена информация о резервах (в частности, резерв по сомнительным долгам, резерв под снижение стоимости материальных ценностей), а также даны пояснения по структуре оценочных обязательств, раскрытых в бухгалтерском балансе. В частности, по данным анализируемого источника информации в 2018 г. ПАО «Газпром» признало такие оценочные обязательства, как обязательства по судебным разбирательствам, обязательства в отношении корректировок цен на газ, обязательства по ликвидации основных средств и восстановлению окружающей среды в связи с пользованием недрами, обязательства по выплате вознаграждений по итогам работы за год и обязательства по оплате отпусков [12].

По данным официального сайта ПАО «Нефтяная компания «Лукойл» на момент подготовки материала данной статьи широкому кругу лиц также была доступна бухгалтерская (финансовая) отчетность указанного хозяйствующего субъекта за 2018 г. и за 9 месяцев 2019 г., в связи с чем анализу была подвергнута отчетность за 2018 г. По данным рассматриваемого источника информации на 31 декабря 2018 г. указанная нефтяная компания признала краткосрочные оценочные обязательства на сумму 3188848 тыс. руб. На указанную 
дату признанных компанией долгосрочных оценочных обязательств не было. В рассматриваемых формах бухгалтерской (финансовой) отчетности информация о резервах (кроме резервного капитала) не выделяется. В пояснениях к формам бухгалтерской (финансовой) отчетности ПАО «Нефтяная компания «Лукойл» отражена информация о резервах (в частности, резерв под обесценение финансовых вложений, резерв под снижение стоимости материальных ценностей, резерв сомнительных долгов). Помимо этого, пояснения также содержат информацию о движении в течение 2018 г. таких оценочных обязательств компании, как обязательства на оплату отпусков, обязательства на годовые премиальные выплаты, обязательства на вознаграждения по программе долгосрочного стимулирования [10].

По информации, полученной с официального сайта ПАО «Нефтяная компания «Роснефть», на момент написания статьи была доступна для широкого круга лиц бухгалтерская (финансовая) отчетность как за 2019 г., так и за 2018 г. Для целей обеспечения сопоставимости информации для целей исследования заявленной проблематике были проанализированы данные за 2018 г. По данным бухгалтерской (финансовой) отчетности на 31 декабря 2018 г. рассматриваемая нефтяная компания признала долгосрочные оценочные обязательства на сумму 56345080 тыс. руб. и краткосрочные оценочные обязательства на сумму 19582179 тыс. руб. Также в составе собственного капитала, помимо резервного капитала, на указанную дату были признаны прочие фонды и резервы; информация о иных резервах в рассматриваемых формах отчетности отдельно не отражена. Согласно пояснениям к формам бухгалтерской (финансовой) отчетности, в 2018 г. компанией была раскрыта информация о резервах, в частности в отношении сомнительной дебиторской задолженности, обесценения финансовых вложений, снижения стоимости материальных ценностей. В рассматриваемом источнике информации также раскрыто движение за 2018 г. таких видов оценочных обязательств, как обязательства по выплате ежегодного вознаграждения по итогам работы за год, обязательства по предстоящей оплате отпускных, обязательства, связанные с экологической деятельностью, обязательства по судебным разбирательствам, обязательства по ликвидации основных средств [11].

Анализ бухгалтерской (финансовой) отчетности рассмотренных представителей экономики России показал, что составители отчетности разделяют такие понятия, как «резерв» и «оценочные обязательства» исходя из их экономической сущности, что находит отражение в представлении финансовых показателей: резервы отражаются как корректировка стоимости активов, в том время как оценочные обязательства отражаются как самостоятельный показатель бухгалтерской (финансовой) отчетности. Это подтверждает сделанный ранее вывод о нетождественности анализируемых понятий.

Полученные результаты исследования понятий «резерв» и «оценочное обязательство» в системе российского нормативно-правового регулирования бухгалтерского учета позволили сделать следующие первоочередные предложения при реализации программы по реформированию указанной системы.

1. Уточнить на законодательном уровне понятие «оценочный резерв», уделяя особое внимание на экономической сущности указанной учетной категории - достижение более достоверной балансовой оценки имущества хозяйствующего субъекта - и ключевые факторы идентификации указанной учетной категории и понятия «оценочное обязательство», что позволит минимизировать ошибки в понятийном аппарате при составлении бухгалтерской (финансовой) отчетности.

2. С целью нивелирования ошибок в понятийном аппарате при разработке учетной политики и раскрытия соответствующей информации в бухгалтерской (финансовой) отчетности хозяйствующего субъекта внести правки в действующую Инструкцию по применению Плана счетов коммерческой организации, которая служит основой для разработки рабочего плана счетов хозяйствующих субъектов, в отношении:

- счета 96 в части наименования, его экономического предназначения и отражения в бухгалтерской (финансовой) отчетности, а также уточнения в части необходимости проведения дисконтирования при оценке обязательств, погашение которых ожидается более чем через 12 месяцев после отчетной даты;

- счетов 14, 59 и 63 путем дополнения в названии ключевой для этой группы резервов характеристики оценочные, а также уточнения способа отражения в бухгалтерской (финансовой) отчетности.

\section{Библиографический список}

1. Международный стандарт финансовой отчетности (IAS) 37 «Оценочные обязательства, условные обязательства и условные активы» (введен в действие на территории Российской Федерации приказом Минфина России от 28.12.2015 № 217н) 
(ред. от 05.08.2019) // СПС «КосультантПлюс» [Электронный ресурс]. - Режим доступа: http://www.consultant.ru/document/ cons_doc_LAW_193594/(дата обращения: 27.03.2020).

2. Приказ Минфина России от 02.07.2010 № 66н (ред. 19.04.2019) «О формах бухгалтерской отчетности организаций» (зарегистрировано в Минюсте России 02.08.2010 № 18023) // СПС «КосультантПлюс» [Электронный ресурс]. - Режим доступа: http://www.consultant.ru/document/cons_doc_LAW_103394/ (дата обращения: 27.03.2020).

3. Приказ Минфина России от 31.10.2000 № 94н (ред. от 08.11.2010) «Об утверждении Плана счетов бухгалтерского учета финансово-хозяйственной деятельности организации и Инструкции по его применению» // СПС «КосультантПлюс» [Электронный ресурс]. - Режим доступа: http://www.consultant.ru/document/cons_doc_LAW_29165/(дата обращения: 27.03.2020).

4. Приказ Минфина России от 13.12.2010 № 167н (ред. от 06.04.2015) «Об утверждении Положения по бухгалтерскому учету «Оценочные обязательства, условные обязательства и условные активы» (ПБУ 8/2010)» // СПС «КосультантПлюс» [Электронный ресурс]. - Режим доступа: http://www.consultant.ru/document/cons_doc_LAW_110328/d0bc983309c89bbc0 2630fab7f1cdb76c1c320c5/ (дата обращения: 27.03.2020).

5. Дружиловская, Т. Ю. Оценочные обязательства и резервы: трактовка и проблемы учета в системах российских и международных стандартов // Международный бухгалтерский учет. - 2016. - № 21 (411). - С. 2-18.

6. Петров, А. М., Мельникова, Л. А. Сравнительный анализ состава и содержания отдельных видов резервов в отечественной и зарубежной практике // Управление экономическими системами. - 2016. - № 7 (89) [Электронный ресурс]. - Режим доступа: https://elibrary.ru/contents.asp?issueid=1607062 (дата обращения: 27.03.2020).

7. Рожнова, О. В. Влияние изменения концептуальных подходов и правил в МСФО на уровень аналитичности отчетной информации // Бухгалтерский учет, анализ и аудит: история, современность и перспективы развития: материалы ХIII Международной научной конференции студентов, аспирантов, преподавателей, Санкт-Петербург, 24 октября 2018 г. СПб.: Изд-во СПбГЭУ, 2018. - С. $62-67$.

8. Рожнова, О. В., Сиднева, В. П. Адаптация руководящих принципов нефинансовой отчетности к российским экономическим условиям // Экономика и предпринимательство. - 2018. - № 6 (95). - С. 1049-1051.

9. Хомяков, М. Ю. Профессиональное суждение и его роль при трансформации и консолидации отчетности компаний нефтегазовой отрасли // Экономика и управление: проблемы, решения. - 2019. - Т. 12. - № 3 (87). - С. 73-77.

10. Бухгалтерская отчетность ПАО «Нефтяная компания «ЛУКОЙЛ» за 2018 год // ПАО «Нефтяная компания «ЛУКОЙЛ»: официальный сайт [Электронный ресурс]. - Режим доступа: http://www.lukoil.ru/InvestorAndShareholderCenter/ RegulatoryDisclosure/RASfinancialstatements (дата обращения: 27.03.2020).

11. Бухгалтерская (финансовая) отчетность ПАО «НК «Роснефть» за 2018 год // ПАО «НК «Роснефть»: официальный сайт [Электронный ресурс]. - Режим доступа: https://www.rosneft.ru/upload/site1/document_report/RSBU_05022019.pdf (дата обращения: 27.03.2020).

12. Годовая бухгалтерская (финансовая) отчетность ПАО «Газпром» за 2018 год // ПАО «Газпром»: официальный сайт [Электронный ресурс]. - Режим доступа: https://www.gazprom.ru/investors/disclosure/reports/2018/ (дата обращения: 27.03.2020).

13. Рейтинг РБК 500 // РБК [Электронный ресурс]. - Режим доступа: https://www.rbc.ru/rbc500/ (дата обращения: 27.03.2020).

\section{References}

1. Mezhdunarodnyi standart finansovoi otchetnosti (IAS) 37 "Otsenochnye obyazatel'stva, uslovnye obyazatel'stva i uslovnye aktivy”: (vveden v deistvie na territorii Rossiiskoi Federatsii prikazom Minfina Rossii ot 28.12.2015 № 217n) (red. ot 05.08.2019) [International Accounting Standard (IAS) 37 "Estinated Liabilities, Contingent Liabilities and Contingent Assets: (put into effect on the territory of the Russian Federation by Order of the Ministry of Finance of Russia No 217n, dated on December 28, 2015) (as amended, dated on August 5, 2019). Legal reference system "ConsultantPlus". Available at: http://www.consultant. ru/document/cons_doc_LAW_193594/(accessed 27.03.2020).

2. Prikaz Minfina Rossii ot 02.07.2010 № 66n (red. 19.04.2019) “O formakh bukhgalterskoi otchetnosti organizatsii (zaregistrirovano v Minyuste Rossii 02.08.2010 № 18023) [Order of the Ministry of Finance of Russia “On the Forms of Accounting Statements of Organizations" № 66n, dated on July 2, 2010 (as amended dated on April 19, 2019) (registered in the Ministry of Justice of Russia No 18023, dated on August 2, 2010)]. Legal reference system "ConsultantPlus". Available at: http://www.consultant. $\mathrm{ru} /$ document/cons_doc_LAW_103394/(accessed 27.03.2020).

3. Prikaz Minfina Rossii ot 31.10.2000 № 94n (red. ot 08.11.2010) “Ob utverzhdenii Plana schetov bukhgalterskogo ucheta finansovo-hozyaistvennoi deyatelnosti organizatsii i Instruktsii po ego primeneniyu [Order of the Ministry of Finance of Russia "On Approval of Chart of Accounts for Accounting of Financial and Economic Entity Activities and Instructions for Its Application" No 94n, 
dated on October 31, 2000 (as amended, dated on November 8, 2010)]. Legal reference system "ConsultantPlus". Available at: http://www.consultant.ru/document/cons_doc_LAW_29165/(accessed 27.03.2020).

4. Prikaz Minfina Rossii ot 13.12.2010 № 167n (red. ot 06.04.2015) “Ob utverzhdenii Polozheniya po bukhgalterskomu uchetu "Otsenochnye obyazatel'stva, uslovnye obyazatel 'stva i uslovnye aktivy" (PBU 8/2010) [Order of the Ministry of Finance of Russia “On Approval of Accounting Regulations “Estimated Liabilities, Contingent Liabilities and Contingent Assets” № 167n, dated on December 13, 2010 (Accounting Regulations 8/2010)]. Legal reference system “ConsultantPlus". Available at: http:// www.consultant.ru/document/cons_doc_LAW_110328/d0bc983309c89bbc02630fab7f1cdb76c1c320c5/ (accessed 27.03.2020).

5. Druzhilovskaya T. U. Otsenochnye obyazatel`stva i rezervy: traktovka i problemy ucheta v sistemakh rossiiskikh i mezhdunarodnykh standartov [Estimated liabilities and reserves: interpretation and accounting issues of Russian and international standards]. Mezhdunarodnyi bukhgalterskii uchet [International Accounting], 2016, no. 21 (2016), pp. 2-18.

6. Petrov A. M., Mel ’nikova L. A. Sravnitel’nyi analiz sostava i soderzhaniya otdel ’nykh vidov rezervov v otechestvennoi i zarubezhnoi praktike [Comparative assessment of structure and the maintenance of separate types of reserves in domestic and foreign practice]. Upravlenie ekonomicheskimi sistemami [Management of Economic Systems], 2016, no. 7 (89). Available at: https:// elibrary.ru/contents.asp?issueid=1607062 (accessed 27.03.2020).

7. Rozhnova, O. V. Vliyanie izmeneniya kontseptual`nykh podkhodov i pravil MSFO na uroven` analitichnosti otchetnoi informatsii [Impact of changes in conceptual approaches and rules of IFRS on the level of analytics of reported information]. Bukhgalterskii uchet, analiz i audit: istoriya, sovremennost' i perspektivy razvitiya: materialy XIII Mezhdunarodnoi nauchnoi konferentsii studentov, aspirantov, prepodavatelei, Sankt-Peterburg, 24 oktyabrya 2018 g. [Accounting, analysis and audit: history, modernity and prospects of development: proceedings of the XIII International scientific conference of students, postgraduates, teachers, Saint-Petersburg, October 24, 2018]. St. Petersburg, Izd-vo SPbGEU, 2018, pp. 62-67.

8. Rozhnova, O. V., Sidneva, V. P. Adaptatsiya rukovodyashchikh printsipov nefinansovoi otchetnosti k rossiiskim ekonomicheskim usloviyam [Adaptation of guiding principles of non-financial reporting to the Russian economic conditions]. Ekonomika i predprinimatel`stvo [Journal of Economy and Entrepreneurship], 2018, no. 6 (95), pp. 1049-1051.

9. Khomyakov M. U. Professional noe suzhdenie i ego rol pri transformatsii i konsolidatsii otchetnosti kompanii neftegazovoi otrasli [Professional judgment and its role in transformation and consolidation of oil and gas companies 'reporting]. Ekonomika i upravlenie: problemy, resheniya [Economics and Management: Problems, Solutions], 2019, vol. 12, no. 3 (87), pp. $73-77$.

10. Bukhgalterskaya otchetnost PAO "Neftyanaya kompaniya "LUKOIL" za 2018 god [Accounting Statements of PJSC "LUKOIL” Oil Company" for 2018]. PJSC "Neftyanaya kompaniya "LUKOIL": ofitsial'nyi sait ["LUKOIL" Oil Company": official website]. Available at: http://www.lukoil.ru/InvestorAndShareholderCenter/RegulatoryDisclosure/RASfinancialstatements (accessed 27.02.2020).

11. Bukhgalterskaya (finansovaya) otchetnost' PAO "NK "Rosneft" za 2018 god [Accounting (Financial) Statements of PJSK “Rosneft"” Oil Company” for 2018]. PAO "NK "Rosneft”": ofitsial nyi sait [PJSK “Rosneft"” Oil Company”: official website]. Available at: https://www.rosneft.ru/upload/site1/document_report/RSBU_05022019.pdf(accessed 27.03.2020).

12. Godovaya bukhgalterskaya (finansovaya) otchetnost` PAO "Gazprom” za 2018 god [Annual Accounting (Financial) Statements PJSK “Gazprom” for 2018]. PAO “Gazprom”: ofitsial'nyi sait [PJSK “Gazprom”: official website]. Available at: https://www. gazprom.ru/investors/disclosure/reports/2018/ (accessed 27.03.2020).

13. Reiting RBK 500 [RBC 500 rating]. RBK [RBC]. Available at: https://www.rbc.ru/rbc500/ (accessed 27.03.2020). 